\title{
New sequence-based data on the relative DNA contents of chromosomes in the normal male and female human diploid genomes for radiation molecular cytogenetics Mikhail V Repin ${ }^{1}$, Pavel I Golubev*2 and Ludmila A Repina ${ }^{3}$
}

\begin{abstract}
Address: ${ }^{1}$ Dzhelepov Laboratory of Nuclear Problems, Joint Institute for Nuclear Research, Dubna, Moscow region, 141980 , Russia, ${ }^{2}$ Department of Physics, Lund University, Lund, S-221 00, Sweden and '3epartment of Radiation Safety of Human Spaceflights, State Research Center of the Russian Federation - Institute for Biomedical Problems, Russian Academy of Sciences, Moscow, 123007, Russia

Email: Mikhail V Repin - Mikhail.Repin@yahoo.com; Pavel I Golubev* - pavel.golubev@nuclear.lu.se; Ludmila A Repina - L_Repina@mail.ru

* Corresponding author
\end{abstract}

Published: 5 June 2009

Molecular Cytogenetics 2009, 2:13 doi:10.1186/1755-8166-2-13
Received: 2 March 2009

Accepted: 5 June 2009

This article is available from: http://www.molecularcytogenetics.org/content/2/1/13

(c) 2009 Repin et al; licensee BioMed Central Ltd.

This is an Open Access article distributed under the terms of the Creative Commons Attribution License (http://creativecommons.org/licenses/by/2.0), which permits unrestricted use, distribution, and reproduction in any medium, provided the original work is properly cited.

\begin{abstract}
Background: The objective of this work is to obtain the correct relative DNA contents of chromosomes in the normal male and female human diploid genomes for the use at FISH analysis of radiation-induced chromosome aberrations.

Results: The relative DNA contents of chromosomes in the male and female human diploid genomes have been calculated from the publicly available international Human Genome Project data. New sequence-based data on the relative DNA contents of human chromosomes were compared with the data recommended by the International Atomic Energy Agency in 200I. The differences in the values of the relative DNA contents of chromosomes obtained by using different approaches for 15 human chromosomes, mainly for large chromosomes, were below $2 \%$. For the chromosomes 13, 17, 20 and 22 the differences were above $5 \%$.

Conclusion: New sequence-based data on the relative DNA contents of chromosomes in the normal male and female human diploid genomes were obtained. This approach, based on the genome sequence, can be recommended for the use in radiation molecular cytogenetics.
\end{abstract}

\section{Background}

The fluorescence in situ hybridization (FISH) technique $[1,2]$ has facilitated rapid detection of stable chromosomal aberrations in human lymphocytes [3] and has become one of the widely used methods in radiation biodosimetry [4-6]. FISH analysis of radiation-induced chromosome aberrations (translocation analysis) was recommended by the International Atomic Energy Agency (IAEA) for estimating absorbed doses of ionizing radiation [7].
Several questions of radiation cytogenetics are connected with the comparison of results obtained by FISH analysis and those by conventional dicentric analysis [8-10] and with the intercomparison of results of FISH analysis with different DNA probes specific for individual chromosomes [11-13]. In this connection an approach based on the calculation of "genomic" frequencies of aberrations in dependence from the fraction of the diploid human genome covered by FISH probes was developed and corresponding equations were derived as early as 1992 [14]. 
It is necessary to know the fractions of the genome covered by FISH probes at the translocation analysis in order to obtain the whole genome equivalent genomic frequencies of chromosome aberrations [14]. In most cases whole chromosome FISH probes are used in radiation cytogenetics. Therefore, it is necessary to know the fractions of the human genome occupied by individual chromosomes.

The relative human DNA contents given in [7] are recommended by the IAEA for calculations of the genomic frequencies of radiation-induced aberrations. These values are derived from the data of Morton on the DNA contents of human chromosomes [15]. However, Morton's estimates of the DNA contents of individual human chromosomes are not exact because they are based on old experimental data obtained by different indirect physical methods [15] including autoradiography [16], image cytometry [17,18], flow cytometry [19-21].

With the increasing accuracy of chromosome aberration analysis [4], the importance of obtaining new exact and objective data on the absolute and relative DNA contents of human chromosomes for radiation cytogenetics is evident.

In the post-genomic era, with the completion of the international Human Genome Project [22], new more accurate data on the length of human chromosomes have been obtained. In this work the publicly available genome sequence data (the numbers of nucleotide base pairs) of the human chromosomes [23] are used for the calculation of relative DNA contents in the normal male and female diploid human genomes.

\section{Results and discussion}

The total sizes of the normal male and female diploid human genomes and the relative DNA contents of chromosomes in the diploid genomes were calculated by using the Human Genome Project data on the chromosome lengths presented in the Ensembl database [23]. The results of these calculations are shown separately for the male and female diploid genomes in Table 1.

The DNA contents of all chromosomes, except chromosome 13, were overestimated in the work of Morton [15] when compared with the Human Genome Project data (Figure 1a and 2a). The maximum difference in these estimates of the human chromosome lengths $(\sim 16 \%)$ was found for chromosome 17 (Figure 2a). The total sizes of the male and female human diploid genomes according to [15] (6 $349 \mathrm{Mb}$ and $6454 \mathrm{Mb}$ for the male and female, correspondingly) were overestimated approximately by $7 \%$ in comparison with the data presented in this work (Table 1).
The comparison of the data from Table 1 and the IAEA manual [7] has shown that the differences in the relative DNA contents of chromosomes in the normal human diploid genomes determined by different approaches are less than in their corresponding absolute DNA contents (Figures $2 a$ and $2 b$ ). As it is seen from Figures $1 b$ and $2 b$, the relative DNA contents of the human chromosomes in the male human diploid genome derived from the Ensembl's data are very close to those derived from Morton's data and recommended by the IAEA [7]. For 15 chromosomes, mainly for large chromosomes, the differences in their relative DNA contents in the human genomes obtained using different approaches are below 2\% (Figure 2b).

However, noticeable differences (larger than 5\%) were found in the relative DNA contents of chromosomes 13, 17,20 and 22 in the human diploid genomes obtained by different approaches (Figure 2b). This result is explained by the poor accuracy of estimates of chromosome lengths by physical methods for small chromosomes than for larger ones. The difference in the relative DNA content of chromosome 17 derived from the human genome sequence data and from the estimates in the work [15] reaches the level of $9.4 \%$ (Figure $2 \mathrm{~b}$ ). Such large differences in the relative DNA contents of individual chromosomes obtained by different approaches could lead to different conclusions, in particular, about the radiosensitivity of these chromosomes and random or non-random distribution of radiation-induced damage in the human chromosomes.

The coefficient 2.05 in the formula of Lucas et al. [14] was re-calculated by using the new sequence-based chromosome lengths from Table 1 . The recalculated coefficients for the male and female human genomes were equal to 2.0533 and 2.0528 , respectively. These values are very close to the previously used value of 2.05 .

Many radiobiological investigations were carried out with the use of DNA probes specific for large chromosomes because the probabilities of their damages by ionizing radiations and the levels of aberrations are highest and the translocation analysis is more effective. It should be noted that taking into account small differences in the values of the relative DNA contents of large chromosomes from work [7] and Table 1, general results and conclusions that were obtained in such investigations would be the same if the approach based on the genome sequence was used. Thus, in most cases the introduction of the correct data on the relative DNA contents of human chromosomes should not be complicated.

In spite of the high-quality sequencing data there are still some uncertainties about the gaps in the genome 
Table I: Sequence-based DNA contents of the human chromosomes.

\begin{tabular}{|c|c|c|c|}
\hline \multirow[t]{2}{*}{ Chromosome } & \multirow[t]{2}{*}{ Chromosome length, bp } & \multicolumn{2}{|c|}{ Relative DNA contents of chromosome pairs in diploid genome, \% } \\
\hline & & Female & Male \\
\hline I & 247249719 & 8.1799 & 8.3135 \\
\hline 2 & 242951149 & 8.0377 & 8.1690 \\
\hline 3 & 199501827 & 6.6002 & 6.7080 \\
\hline 4 & 191273063 & 6.3280 & 6.4313 \\
\hline 5 & 180857866 & 5.9834 & 6.0811 \\
\hline 6 & 170899992 & 5.6540 & 5.7463 \\
\hline 7 & 158821424 & 5.2544 & 5.3402 \\
\hline 8 & 146274826 & 4.8393 & 4.9183 \\
\hline 9 & 140273252 & 4.6407 & 4.7165 \\
\hline 10 & 135374737 & 4.4787 & 4.5518 \\
\hline 11 & 134452384 & 4.4482 & 4.5208 \\
\hline 12 & I32 349534 & 4.3786 & 4.4501 \\
\hline 13 & II4 I42980 & 3.7763 & 3.8379 \\
\hline 14 & 106368585 & 3.5191 & 3.5765 \\
\hline 15 & 100338915 & 3.3196 & 3.3738 \\
\hline 16 & 88827254 & 2.9387 & 2.9867 \\
\hline 17 & 78774742 & 2.6062 & 2.6487 \\
\hline 18 & 76117153 & 2.5182 & 2.5594 \\
\hline 19 & 63811651 & 2.1111 & 2.1456 \\
\hline 20 & 62435964 & 2.0656 & 2.0993 \\
\hline 21 & 46944323 & $|.553|$ & 1.5785 \\
\hline 22 & 49691432 & 1.6440 & 1.6708 \\
\hline$x$ & 154913754 & 5.1251 & $2.6044 \dagger$ \\
\hline$Y$ & 57772954 & & $0.9713 \dagger$ \\
\hline The size of the diploid female genome & 6045293052 & 100 & -- \\
\hline The size of the diploid male genome & 5948152252 & -- & 100 \\
\hline
\end{tabular}

The sequence-based absolute and relative DNA contents of the human chromosomes in the male and female diploid genomes calculated by using the international Human Genome Project data from Ensembl database, release 52 - December 2008 [23].

$\dagger$ Relative DNA contents of single $X$ and single $Y$ chromosomes in the male human diploid genome were calculated

sequence and human genetic variations [22]. Recently, a considerable degree of genetic variations ranging to megabases in size was shown [24]. The 1000 Genomes project could provide a deeper understanding of human genetic variations [25].

Nevertheless, new values of the relative DNA contents of chromosomes in the normal human diploid genome based on the international Human Genome Project sequence data could be considered as the best data to date.

\section{Conclusion}

At present we have the unique opportunity to use precise sequence-based parameters of the reference human genome including the relative DNA contents of chromosomes in the human genome instead of the approximate estimates that have been done by indirect methods at the initial stage of the Human Genome Project. New sequence-based data on the relative DNA contents of chromosomes in the normal male and female human dip- loid genomes were obtained. The approach, based on the DNA sequence data, can be recommended for the use in radiation molecular cytogenetics.

\section{Methods}

The data on the lengths of each human chromosome were taken from the public Ensembl database http:// www.ensembl.org/, release 52 - December 2008 [23]. The sequence-based relative DNA contents of the male and female human diploid genomes occupied by each pair of autosome chromosomes were calculated (Table 1). Briefly, the total sizes of the male and female human diploid genomes were obtained by addition of the lengths of all 46 chromosomes: 22 pairs of the autosomes and two $\mathrm{X}$ chromosomes for the female genome and 22 pairs of the autosomes and two sex chromosomes $\mathrm{X}$ and $\mathrm{Y}$ for the male genome.

For each pair of the autosomes the relative DNA contents were calculated as a ratio of the doubled DNA size to the 


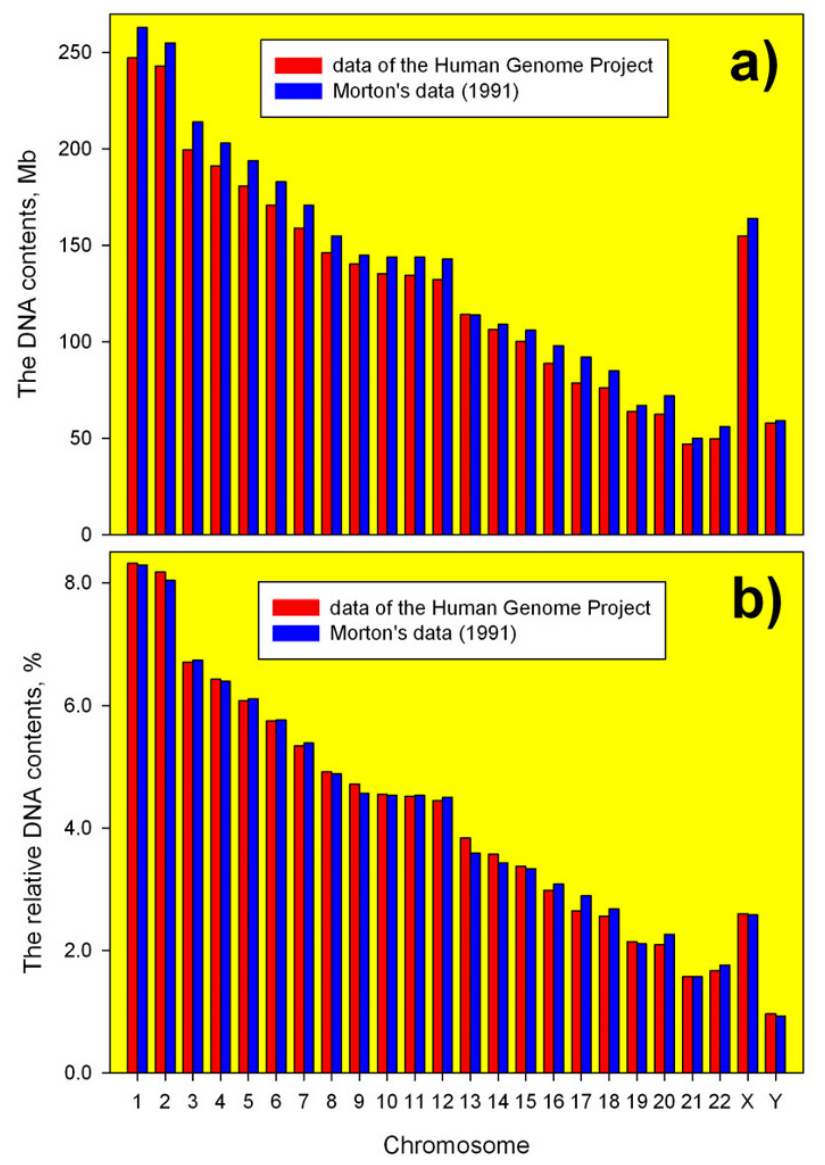

Figure I

The absolute (a) and relative (b) DNA contents of the human chromosomes obtained by different approaches. a). The absolute DNA contents of the human chromosomes according to the data of Morton [15] and the Human Genome Project data [23]. b). The relative DNA contents of the chromosomes in the male human diploid genome from [7] and results of this work (see Table I).

size of diploid female and male genomes, correspondingly. Similarly the relative DNA content of the sex chromosome $\mathrm{X}$ in the female genome was calculated. The single DNA contents in the genome were used to obtain the relative DNA content of the sex chromosomes in the diploid male human genome.

In the formula derived by Lucas et al. [14] $F_{p}=2.05 f_{p}(1-$ $\left.f_{p}\right) F_{G^{\prime}}$, relating the translocation frequency, $F_{p}$, measured using FISH to the genomic translocation frequency, $F_{G^{\prime}}$ where $f_{p}$ is the fraction of the genome covered by the composite probe, the coefficient 2.05 was recalculated separately for the human female and male genomes by using the sequence-based relative DNA contents of the chromosomes from Table 1:

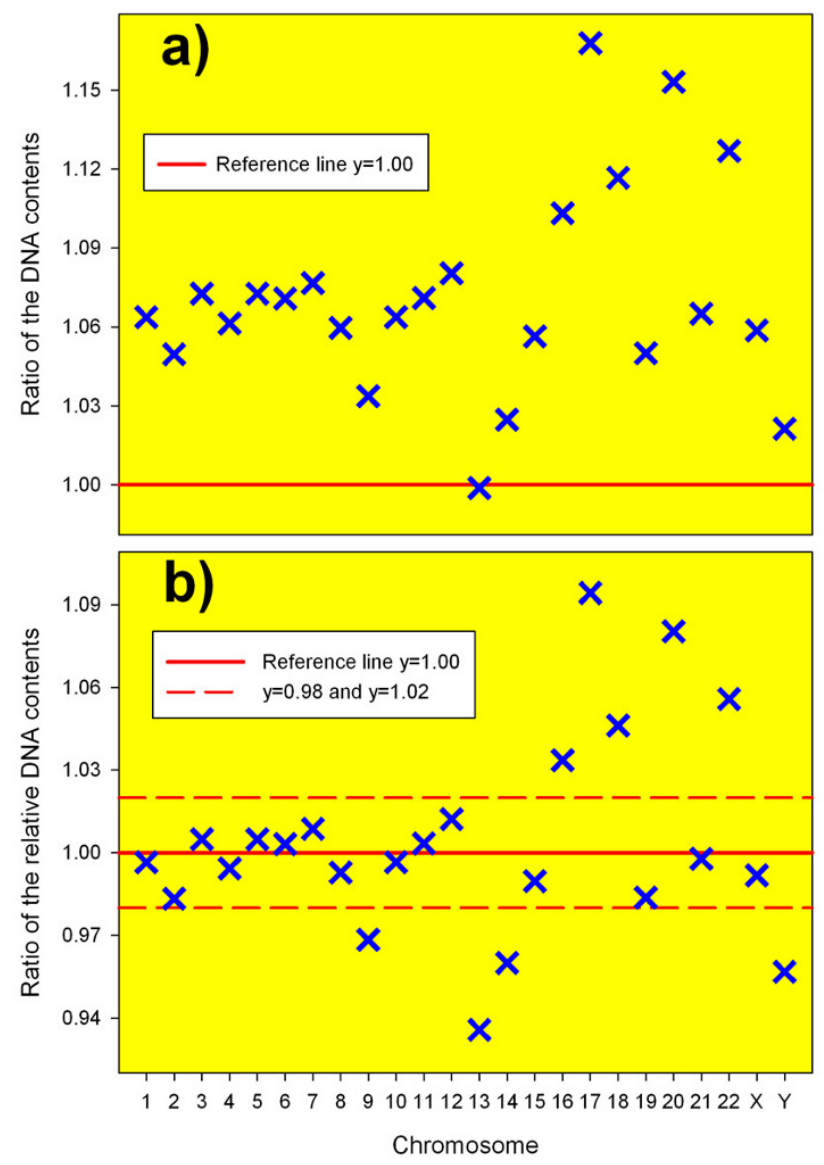

Figure 2

Ratios of the absolute (a) and relative (b) DNA contents of the human chromosomes obtained by different approaches. a). Ratios between absolute DNA contents of the chromosomes in the male human diploid genome published by Morton [15] and Human Genome Project data [23]. b). Ratios between relative DNA contents of the chromosomes in the male human diploid genome from [7] and results of this work (see Table I).

$$
K=\frac{2}{1-\sum_{i=1}^{46} C_{i}^{2}}
$$

where $C_{i}$ is a fraction of the DNA content of the $i$-chromosome in the male or female human diploid genome.

\section{Competing interests}

The authors declare that they have no competing interests.

\section{Authors' contributions}

MVR wrote the manuscript and PIG and LAR contributed significant editorial input and original ideas. All authors read and approved the final manuscript. 


\section{Acknowledgements}

The authors would like to thank Douglas Dijulio from the Lund University for the manuscript preparation.

\section{References}

I. Pinkel D, Straume T, Gray JW: Cytogenetic analysis using quantitative, high-sensitivity, fluorescence hybridization. Proc Natl Acad Sci USA 1986, 83:2934-2938.

2. Pinkel D, Landegent J, Collins C, Fuscoe J, Segraves R, Lucas J, Gray J: Fluorescence in situ hybridization with human chromosomespecific libraries: Detection of trisomy 21 and translocations of chromosome 4. Proc Natl Acad Sci USA 1988, 85:9|38-9|42.

3. Lucas JN, Tenjin T, Straume T, Pinkel D, Moore D II, Litt M, Gray JW: Rapid human chromosome aberration analysis using fluorescence in situ hybridization. Int J Radiat Biol 1989, 56:35-44.

4. Kanda R: Improvement of accuracy of chromosome aberration analysis for biological radiation dosimetry. J Radiat Res (Tokyo) 2000, 4 I: I-8.

5. Tucker JD: FISH cytogenetics and the future of radiation biodosimetry. Radiat Prot Dosimetry 2001, 97:55-60.

6. Edwards AA, Lindholm C, Darroudi F, Stephan G, Romm H, Barquinero J, Barrios L, Caballin MR, Roy L, Whitehouse CA, et al.: Review of translocations detected by FISH for retrospective biological dosimetry applications. Radiat Prot Dosimetry 2005, I I 3:396-402.

7. IAEA: Cytogenetic analysis for radiation dose assessment: a manual Vienna: IAEA; 200I.

8. Kanda R, Hayata I: Comparison of the yields of translocations and dicentrics measured using conventional Giemsa staining and chromosome painting. Int J Radiat Biol 1996, 69:70I-705.

9. Lindholm C, Luomahaara S, Koivistoinen A, llus T, Edwards AA, Salomaa S: Comparison of dose-response curves for chromosomal aberrations established by chromosome painting and conventional analysis. Int J Radiat Biol I998, 74:27-34.

10. Nakano M, Kodama Y, Ohtaki K, Itoh M, Delongchamp R, Awa AA, Nakamura N: Detection of stable chromosome aberrations by FISH in A-bomb survivors: comparison with previous solid Giemsa staining data on the same $\mathbf{2 3 0}$ individuals. Int J Radiat Biol 2001, 77:971-977.

II. Braselmann H, Kulka U, Huber R, Figel HM, Zitzelsberger H: Distribution of radiation-induced exchange aberrations in all human chromosomes. Int J Radiat Biol 2003, 79:393-403.

12. Anderson RM, Sumption ND, Papworth DG, Goodhead DT: Chromosome breakpoint distribution of damage induced in peripheral blood lymphocytes by densely ionizing radiation. Int J Radiat Biol 2006, 82:49-58.

13. Lindholm C, Romm H, Stephan G, Schmid E, Moquet J, Edwards A: Intercomparison of translocation and dicentric frequencies between laboratories in a follow-up of the radiological accident in Estonia. Int J Radiat Biol 2002, 78:883-890.

14. Lucas JN, Awa A, Straume T, Poggensee M, Kodama Y, Nakano M, Ohtaki K, Weier H-U, Pinkel D, Gray J, et al.: Rapid translocation frequency analysis in humans decades after exposure to ionizing radiation. Int I Radiat Biol 1992, 62:53-63.

15. Morton NE: Parameters of the human genome. Proc Natl Acad Sci USA I99I, 88:7474-7476.

16. Korenberg JR, Engels WR: Base ratio, DNA content, and quinacrine-brightness of human chromosomes. Proc Natl Acad Sci USA 1978, 75:3382-3386.

17. Mayall BH, Carrano AV, Moore DH 2nd, Ashworth LK, Bennett DE, Mendelsohn ML: The DNA-based human karyotype. Cytometry 1984, 5:376-385.

18. Mendelsohn ML, Mayall BH, Bogart E, Moore DH 2nd, Perry BH: DNA content and DNA-based centromeric index of the 24 human chromosomes. Science 1973, I79: I I26-II 29.

19. Harris P, Boyd E, Young BD, Ferguson-Smith MA: Determination of the DNA content of human chromosomes by flow cytometry. Cytogenet Cell Genet 1986, 4 I: I4-2I.

20. Langlois RG, Yu L-C, Gray JW, Carrano AV: Quantitative karyotyping of human chromosomes by dual beam flow cytometry. Proc Natl Acad Sci USA 1982, 79:7876-7880.

21. Tiersch TR, Chandler RW, Wachtel SS, Elias S: Reference standards for flow cytometry and application in comparative studies of nuclear DNA content. Cytometry 1989, 10:706-710.
22. International Human Genome Sequencing Consortium: Finishing the euchromatic sequence of the human genome. Nature 2004, 43 I:93I-945.

23. Hubbard TJ, Aken BL, Ayling S, Ballester B, Beal K, Bragin E, Brent S, Chen Y, Clapham P, Clarke L, et al.: Ensembl 2009. Nucleic Acids Res 2009, 37:D690-697.

24. Sebat J, Lakshmi B, Troge J, Alexander J, Young J, Lundin P, Maner S, Massa H, Walker M, Chi M, et al.: Large-scale copy number polymorphism in the human genome. Science 2004, 305:525-528.

25. Siva N: I000 Genomes project. Nat Biotechnol 2008, 26:256.
Publish with Biomed Central and every scientist can read your work free of charge

"BioMed Central will be the most significant development for disseminating the results of biomedical research in our lifetime. "

Sir Paul Nurse, Cancer Research UK

Your research papers will be:

- available free of charge to the entire biomedical community

- peer reviewed and published immediately upon acceptance

- cited in PubMed and archived on PubMed Central

- yours - you keep the copyright 